\title{
THE PREVENTION OF EXPERIMENTAL CLOSTRIDIUM NOVYI AND CL. PERFRINGENS GAS GANGRENE IN HIGH-VELOCITY MISSILE WOUNDS BY ACTIVE IMMUNISATION
}

\author{
N. A. BoYD*, R. O. Thomson AND P. D. WALKeR \\ Tidworth Military Hospital, Tidworth, Hampshire, and Wellcome \\ Research Laboratories, Langley Court, Beckenham, Kent
}

SEVERAL vaccines have been developed against the gas-gangrene group of organisms, and their use in animals and man is well documented. In most cases the immune response obtained with these vaccines has been determined in terms of the level of circulating antitoxin, but there are a number of reports in which a challenge by toxin or virulent culture has been used to measure protection. In general, it has not been found possible to correlate the level of circulating antitoxin or the protection against artificial challenge with the degree of protection afforded against natural challenge.

Penfold, Tolkhurst and Wilson (1941) investigated the responses of guinea-pigs and man to injections of Clostridium perfringens fluid toxoid and alum-precipitated toxoid; these workers showed that although fluid toxoid in guinea-pigs was a poor antigen, it was very much improved by the addition of alum. A single injection of the alum-precipitated vaccine produced circulating antitoxin in man that was still demonstrable $5 \mathrm{mth}$ later. When immune sera taken from these subjects $2 \mathrm{wk}$ after immunisation were injected into mice, the mice were protected against an intraperitoneal challenge with $\mathrm{Cl}$. perfringens culture.

Tytell et al. (1947) investigated the antigenicity of alum-precipitated $\mathrm{Cl}$. perfringens and $\mathrm{Cl}$. novyi culture products in guinea-pigs and man; they used a toxin challenge for the animals and measured antitoxin titres in the human subjects. They showed that the response to three doses of vaccine was greatly improved if the third dose was delayed up to $40 \mathrm{wk}$. In a study of the value of small doses of concentrated toxoids as vaccines, Robertson and Keppie (1943) used as a method of challenge the injection of $\mathrm{Cl}$. novyi or Cl. septicum spores or a fresh culture of $\mathrm{Cl}$. perfringens with 5 per cent. calcium chloride into the muscle of guineapigs. Two injections of toxoid were given $3 \mathrm{wk}$ apart, and the animals were challenged 8-20 wk later. There were four deaths in a group of 61 immunised animals, compared with 48 deaths in 51 controls.

Satisfactory vaccines have also been produced against $\mathrm{Cl}$. perfringens type A by Stewart (1942), and Saltykov, Rozepov and Zemskov (1945), and against $\mathrm{Cl}$. novyi by Shneerson (1957).

In addition to their association with gas gangrene, the clostridia are responsible for a number of unrelated diseases in sheep, cattle and other animals. Much experimental work has been done in developing satisfactory vaccines against these diseases (Sterne et al., 1962; Thomson and Batty, 1967; Thomson et al., 1969). Since extracellular toxins play a major role in the pathology of these diseases, vaccines containing single and multiple components have been developed which, on injection, produced adequately sustained levels of circulating antitoxin to prevent outbreaks of disease occurring in the field. It is possible that the same type of vaccine may be of value in the prophylaxis of gas gangrene.

Received 15 Jan. 1972; accepted 30 Mar. 1972.

* Present address: Royal Herbert Hospital, Woolwich, London, S.E.18.

J. MED. MICROBIOL.-VOL. 5 (1972) 
In the previous paper (Boyd, Walker and Thomson, 1972), we have considered passive immunisation as a method of protecting sheep against gas gangrene after the contamination of high-velocity missile wounds with spores of $\mathrm{Cl}$. novyi type A. In the present paper the efficacy of active immunisation in preventing the disease in the same experimental model is reported, the challenge species being $\mathrm{Cl}$. novyi type $\mathrm{A}$ and $\mathrm{Cl}$. perfringens type $\mathrm{A}$.

\section{MATERIALS AND METHODS}

The experimental model. This is described in the previous paper (Boyd et al., 1972).

Experimental vaccine. This was a mixed vaccine consisting of $\mathrm{Cl}$. novyi alpha toxoid 3.0 units per $\mathrm{ml}, \mathrm{Cl}$. septicum alpha toxoid 4.2 units per $\mathrm{ml}$ and $\mathrm{Cl}$. perfringens type A alpha toxoid 3.0 units per $\mathrm{ml}$. The vaccine contained 2.5 per cent. (w/v) alum as an adjuvant and 0.01 per cent. thiomersalate as preservative.

Immunisation procedure. Sheep were immunised with two 2-ml doses given subcutaneously and spaced $1 \mathrm{mth}$ apart. Blood samples were taken for titration of antitoxin before immunising and at 14 days after the second injection.

$C l$. novyi challenge. The sheep were divided into six groups, each comprising animals with high and low titres of $\mathrm{Cl}$. novyi alpha antitoxin. The first group was challenged in the left leg $11 \mathrm{wk}$ after vaccination by the standard muscle wound using the spore suspension of $\mathrm{Cl}$. novyi type A described previously. Subsequent groups were challenged at 10-12-wk intervals, the last being challenged $1 \mathrm{yr}$ after vaccination. At the time of each challenge, two unprotected sheep were used as controls.

$\mathrm{Cl}$. perfringens challenge. In order to determine the effectiveness of $\mathrm{Cl}$. perfringens immunisation, 20 sheep were selected from those that survived the $\mathrm{Cl}$. novyi challenge. These were divided into four groups, the first group being challenged with $\mathrm{Cl}$. perfringens in the right leg by the standard method 43 wk after vaccination. The remaining groups were challenged at 44, 45 and $56 \mathrm{wk}$ after vaccination. Two unvaccinated sheep were challenged at the same time as each of the four groups and these served as controls. The challenge consisted of a 5-hr growth of $\mathrm{Cl}$. perfringens type A strain CN1491 (Wellcome Culture Collection) in Robertson's meat broth containing 0.5 per cent. glucose. These cultures contained no spores and about $3 \times 10^{9}$ organisms per ml (Brown's tube no. 10). One millilitre of culture was placed on a piece of battledress cloth immediately before challenge and formed a damp area of 1-2 cm diameter in the centre of the cloth through which the bullet passed.

Antitoxin determination. Blood samples were taken before and after vaccination, at challenge and $3 \mathrm{wk}$ after challenge. Antitoxin in the serum from these samples was assayed in mice by determining the extent to which it neutralised specific toxin. Titres of less than 0.1 unit per $\mathrm{ml}$ for $\mathrm{Cl}$. novyi and less than 0.005 unit per $\mathrm{ml}$ for $\mathrm{Cl}$. perfringens were not determined.

\section{RESULTS \\ Cl. novyi challenge}

The response to the $C l$. novyi alpha component of the gas-gangrene vaccine is shown in table I. All 37 sheep used had less than 0.1 unit of antitoxin per $\mathrm{ml}$ before vaccination and it was therefore likely that they had had no previous experience of the antigen. No sheep had less than 2 units of antitoxin 2 wk after vaccination. In the interval between vaccination and challenge there was a considerable fall in titre, but the concentration rose markedly in those vaccinated sheep that survived the challenge. This indicates the severity of the challenge and the satisfactory state of immunity in the sheep. 
There were 12 unvaccinated controls and, of these, 11 died of gas gangrene within $48 \mathrm{hr}$; one animal died under anaesthesia.

Of the 37 protected sheep, three died of gas gangrene between 3 and 6 days after challenge. The level of protection in these sheep is shown in table II.

TABLE I

Clostridium novyi alpha-antitoxin titres obtained in sheep at various times before and after vaccination with two injections of experimental gas-gangrene vaccine given at an interval of $1 \mathrm{mth}$ and subsequently challenged with $\mathrm{Cl}$. novyi

\begin{tabular}{|c|c|c|c|c|c|c|}
\hline \multirow{2}{*}{ Group } & \multirow{2}{*}{$\begin{array}{l}\text { Number of } \\
\text { sheep }\end{array}$} & \multirow{2}{*}{$\begin{array}{l}\text { Interval between } \\
\text { last dose of } \\
\text { vaccine and } \\
\text { challenge* (wk) }\end{array}$} & \multicolumn{4}{|c|}{$\begin{array}{l}\text { Geometric mean of } \mathrm{Cl}_{\text {. novyi antitoxin titres }} \\
\text { in each group (units per ml serum) }\end{array}$} \\
\hline & & & $\begin{array}{l}\text { immediately } \\
\text { before } \\
\text { vaccination }\end{array}$ & $\begin{array}{l}2 \mathrm{wk} \text { after } \\
\text { vaccination }\end{array}$ & $\begin{array}{c}\text { at } \\
\text { challenge }\end{array}$ & $\begin{array}{l}2 \mathrm{wk} \text { after } \\
\text { challenge }\end{array}$ \\
\hline $\begin{array}{l}1 \\
2 \\
3 \\
4 \\
5 \\
6\end{array}$ & $\begin{array}{l}6 \\
6 \\
6 \\
6 \\
6 \\
7\end{array}$ & $\begin{array}{l}11 \\
22 \\
28 \\
38 \\
46 \\
55\end{array}$ & $\begin{array}{l}<0.1 \\
<0.1 \\
<0.1 \\
<0.1 \\
<0.1 \\
<0.1\end{array}$ & $\begin{array}{l}18 \cdot 8 \\
13 \cdot 1 \\
15 \cdot 3 \\
11 \cdot 3 \\
14 \cdot 7 \\
19 \cdot 3\end{array}$ & $\begin{array}{l}2 \cdot 8 \\
0 \cdot 43 \\
0 \cdot 23 \\
0 \cdot 37 \\
0 \cdot 28 \\
0 \cdot 54\end{array}$ & $\begin{array}{l}119 \\
708 \\
383 \\
134 \\
585 \\
468\end{array}$ \\
\hline
\end{tabular}

* See Methods section for details.

TABLE II

Antitoxin titres of three vaccinated sheep that died of gas gangrene after being challenged with spores of Cl. novyi type $\mathrm{A}$

\begin{tabular}{c|c|c|c}
\hline \multirow{2}{*}{ Group } & $\begin{array}{c}\text { Time of death } \\
\text { after challenge } \\
\text { (days) }\end{array}$ & \multicolumn{2}{|c}{$\begin{array}{c}\text { Cl. novyi antitoxin titre } \\
\text { (units per ml) }\end{array}$} \\
\cline { 3 - 4 } & $\begin{array}{c}\text { 2 wk after } \\
\text { vaccination }\end{array}$ & at challenge \\
\hline 1 & 6 & $10-20$ & $2-5$ \\
2 & 3 & $2-5$ & $<0.1$ \\
6 & 3 & 10 & $0.1-0.2$ \\
\hline
\end{tabular}

All three survived longer than the controls and to this extent vaccination gave them some protection. The antitoxin titres of the two from groups 2 and 6 were the lowest in the two groups and well below the geometric means for these groups. On the other hand, the sheep from group 1 that died had a titre comparable with those of vaccinated survivors.

The survival rate within 90 per cent. confidence limits following the $\mathrm{Cl}$. novyi challenge was $2.5-8.5$ per cent. in the control sheep and $82.5-94.5$ per cent. in the vaccinated groups. 


\section{Cl. perfringens type $A$ challenge}

The $C l$. perfringens alpha-antitoxin titres of the sheep selected for challenge with this organism are shown in table III. In some sheep there were significant titres before vaccination and this indicates previous experience of the antigen. Antitoxin was not measured immediately after vaccination, but the titres observed in all groups at the time of challenge suggested that vaccination had resulted in a high level of immunity. A marked increase in the level of circulating antitoxin occurred after challenge.

\section{TABLE III}

The Cl. perfringens alpha-antitoxin titres of sheep before vaccination, at the time of challenge and 3 wk after challenge

\begin{tabular}{|c|c|c|c|c|c|}
\hline \multirow{2}{*}{ Group } & \multirow{2}{*}{$\begin{array}{l}\text { Number of } \\
\text { sheep }\end{array}$} & \multirow{2}{*}{$\begin{array}{l}\text { Interval between } \\
\text { last dose of } \\
\text { vaccine and } \\
\text { challenge (wk) }\end{array}$} & \multicolumn{3}{|c|}{$\begin{array}{l}\text { Geometric mean of } \mathrm{Cl} \text {. perfringens titres } \\
\text { (units per ml serum) }\end{array}$} \\
\hline & & & $\begin{array}{l}\text { immediately } \\
\text { before } \\
\text { vaccination }\end{array}$ & at challenge & $\begin{array}{l}3 \text { wk after } \\
\text { challenge }\end{array}$ \\
\hline 1 & 4 & 43 & 0.005 & $0 \cdot 38$ & $8 \cdot 7$ \\
\hline 2 & 4 & 44 & 0.006 & $0 \cdot 16$ & $12 \cdot 6$ \\
\hline 3 & 4 & 45 & 0.006 & 0.03 & $3 \cdot 7$ \\
\hline 4 & 8 & 56 & 0.014 & $0 \cdot 13$ & $9 \cdot 2$ \\
\hline
\end{tabular}

Two of the unvaccinated controls from groups 2 and 3 survived and the remaining six died of gas gangrene within 4 days. Of the 20 immunised animals challenged in this series, only one died of gas gangrene. This was a group-4 animal with a pre-challenge titre of $0.01-0.02$ unit per $\mathrm{ml}$. The survival rate, within 90 per cent. confidence limits, following the $\mathrm{Cl}$. perfringens type A challenge was 12-50 per cent. for the control group and 83-94.5 per cent. for the vaccinated group.

\section{Pathology associated with $\mathrm{Cl}$. novyi and $\mathrm{Cl}$. perfringens challenges}

Within a week of wounding, the protected animals all developed a pustular abscess within the adductor group of muscles. The pathology exactly mimicked that seen in those sheep treated with antitoxin alone (Boyd et al., 1972). It was not always possible to identify organisms in the pus, because frequently at necropsy performed $3 \mathrm{wk}$ after challenge, complete lysis of the organisms had occurred. In sheep that were alive many months after challenge, the abscesses had pointed and drained and there remained only a fibrous track.

\section{Discussion}

The results show that the experimental gas-gangrene vaccine protected sheep against a massive $C l$. novyi or $C l$. perfringens challenge for at least a year after 
immunisation. At this time the concentrations of circulating antitoxin were quite low, and in some individuals they fell below the minimum level demonstrable with our tests.

Gas gangrene has a relatively short incubation period and, as has been shown in the previous paper, antitoxin is of little benefit if given more than $21 \mathrm{hr}$ after challenge. Such levels of antitoxin as were present in the actively immunised sheep must, therefore, have been sufficient to contain the disease since it is unlikely that an anamnestic response to toxin produced in the wound could have provided sufficient antitoxin in time to contribute to the control of the disease.

It therefore seems that even antitoxin concentrations of less than $0 \cdot 1$ unit per $\mathrm{ml}$ of serum were sufficient to prevent infection and that an effective amount of antitoxin may have been present before the animal was challenged. The fact that antitoxin titres were increased to quite high levels after challenge suggested two things: first, that sufficient toxin was produced by growth of the organism in the wound to provoke a secondary response, and second, that the effective immune response of the animal was directed not against the organism but against the toxin that it produced, otherwise growth and toxin production would not have occurred in the wound. This is confirmed by the fact that $\mathrm{Cl}$. novyi and $\mathrm{Cl}$. perfringens could be cultured from the wound several weeks after challenge and lends weight to the contention that the necessary type of immunity is antitoxic.

While it is unwise to draw conclusions on the efficiency of a vaccine in man from the results obtained in sheep, the fact that protective levels of circulating antitoxin have been established should encourage attempts to establish the conditions necessary for attaining the same levels in man and maintaining them. It is not unreasonable to assume that the protective level required in man may be comparable to that in sheep. It should be noted that, at least in the case of $\mathrm{Cl}$. novyi, the severity of the challenge given to the test sheep was much greater than would be encountered in man even in war. With regard to $\mathrm{Cl}$. perfringens, one could imagine circumstances in which contamination was very great, i.e., in wounds grossly contaminated with faeces or manured soil or in wounds involving rupture of the large intestine. There seems, therefore, to be a case for an investigation into the antitoxin responses that clostridial vaccines provoke in man, in order to be able to develop satisfactory gas gangrene vaccines. These might find a place not only in the protection of forces engaged in combat but also in the protection of sections of the civil population from gas gangrene as a complication of road accidents, major disasters or surgery, e.g., the surgery of obliterative arterial disease (Parker, 1969).

\section{SUMMARY}

Sheep were immunised with a mixed vaccine containing the toxoids of Clostridium perfringens, $\mathrm{Cl}$. septicum and $\mathrm{Cl}$. novyi and challenged at different intervals after immunisation. The sheep were wounded and challenged in the thigh muscle by a high-velocity bullet that passed through a piece of battledress 
impregnated with a suspension of either $C l$. novyi spores or $C l$. perfringens culture.

Immunisation was almost completely effective in preventing the onset of gas gangrene due to $C l$. novyi even 1 yr after immunisation, the survival rate being 82.5-94.5 per cent. within 90 per cent. confidence limits (rate for unvaccinated controls: $2 \cdot 5-8 \cdot 5$ per cent.). Vaccinated sheep that survived challenge with $C l$. novyi were later challenged with $C l$. perfringens and survived this, the rate of survival being 83-94.5 per cent. (rate for unvaccinated controls: 12-50 per cent.). The role that such a vaccine might play in the prevention of gas gangrene in man is discussed.

The work described in this paper and the previous one was facilitated by the following, to whom we extend our sincere thanks: Dr F. Beswick, Medical Director, C.D.E.E., Porton, for advice; Dr Patterson of Allington Farm, Porton, who supplied the sheep; the staff of The Pathology Department, C.D.E.E., Porton, who prepared most of the histological sections; the staff of The Photographic Section, C.D.E.E., Porton, who prepared slides and photographs; Dr J. Keppie, M.R.E., Porton, who supplied the $C l$. novyi challenge culture; Mr S. Madden, M.R.E., Porton, who advised on wound ballistics. We also thank Sgt Hughes, R.A.M.C., for his unfailing help as laboratory technician and shepherd; Miss E. Hart, Wellcome Research Laboratories (W.R.L.), Beckenham, who titrated the sheep sera; and Mr W. H. Foster, W.R.L., Beckenham, who supplied the experimental gasgangrene vaccine.

This work was incorporated in a thesis for the degree of Master of Surgery submitted to London University in 1971 by N. A. Boyd.

\section{REFERENCES}

Boyd, N. A., Walker, P. D., AND Thomson, R. O. 1972. The prevention of experimental Clostridium novyi gas gangrene in high-velocity missile wounds by passive immunisation. J. Med. Microbiol., 5, 459.

PARKER, M. T. 1969. Postoperative clostridial infections in Britain. Br. Med. J., 3, 671.

Penfold, W. J., Tolkhurst, J. C., AND Wilson, D. 1941. Active immunisation against gas gangrene and tetanus. J. Path. Bact., 52, 187.

RoBerTsON, M., AND KePPIE, J. 1943. Gas gangrene. Active immunisation by means of concentrated toxoids. Lancet, $2,311$.

Saltykov, R. A., Rezepov, F. F., AND Zemskov, E. M. 1959. Rate of development of immunity following revaccination with anaerobic toxoids. Byull. eksp. Biol. Med., 47 (8), 81 (in Russian).

ShNEERSON, A. N. 1957. Comparative study of immunogenic characteristics of anatoxin of B. oedematiens. Zh. Mikrobiol. epidem. Immunobiol., 28 (4), 146.

Sterne, M., Batty, Irene, Thomson, A., AND Robertson, J. M. 1962. Immunisation of sheep with multi-component clostridial vaccines. Vet. Rec., 74, 909.

STEWART, S. E. 1942. Antigenic values of Clostridium perfringens (Clostridium welchii) toxoid in prevention of gas gangrene. War Med., Chicago, $2,87$.

Thomson, R. O., AND BATTy, IRENe 1967. Experimental clostridial oil emulsion vaccines. Bull. Off. int. epizoot., 67, 1569.

Thomson, R. O., Batty, Irene, Thomson, A., Kerry, J. B., Epps, H. B. G., and Foster, W. H. 1969. The immunogenicity of a multicomponent clostridial oil emulsion vaccine in sheep. Vet. Rec., 85, 81 .

Tytell, A. A., Logan, M. A., Tytell, Alice G., AND TePper, J. 1947. Immunization of humans and animals with gas gangrene toxoids. J. Immun., 55, 233. 